\begin{tabular}{|c|c|c|}
\hline PORT SAID ENGINEERING RESEARCH JOURNAL & Faculty of Engineering - Port Said University \\
\hline & No. 2 Peptember 2020 & pp. 106-113 \\
\hline (Mechanical Production Engineering)
\end{tabular}

\title{
Experimental Investigation of Generated Surface Roughness in Hard Turning of Ti6Al4V Using Coated Ceramic and CBN Inserts
}

\author{
Al Shimaa Abdelnasser ${ }^{1}$, Azza Barakat ${ }^{2}$, Samar Elsanabary ${ }^{3}$, Ahmed Nassef $^{4}$
}

Received: 20 June 2020; Accepted: 5 July 2020

\begin{abstract}
Surface finish of machined parts is a significant quality mark for a range of applications such as aerospace, automotive, power transmission and generation. Therefore, optimization of surface roughness is the key factor for reliability in machining difficult-to-cut materials such as titanium-based alloys. In this study, an investigation into hard turning of Ti6Al4V alloys with varying process parameters and cutting tool materials was carried out. This study aims to compare the generated surface roughness when turning Ti6Al4V alloys using CBN and coated ceramic inserts, independently, under the same values of feed rate, cutting speed and depth of cut. The experiments were designed using Taguchi L9 and the exponential results were examined by the analysis of variance (ANOVA). The effect of process parameters and their interactions on generated surface roughness was evaluated for the two inserts. It was found improvement of surface roughness by $34 \%$ was achieved when using coated ceramic insert compared with the results obtained using CBN insert under the same range cutting conditions. CBN insert gave a better result at smallest depth of cut $(0.15 \mathrm{~mm})$, low feed rate $(0.1 \mathrm{~mm} / \mathrm{rev})$ and high cutting speed $(100$ $\mathrm{m} / \mathrm{min})$ while coated ceramic tool gave a minimum surface roughness at depth of cut $(0.2 \mathrm{~mm})$, feed rate $(0.1 \mathrm{~mm} / \mathrm{rev})$ and high cutting speed $(100 \mathrm{~m} / \mathrm{min})$.
\end{abstract}

Keywords: Ti6Al4V, turning, coated ceramic insert, CBN insert, surface roughness

\section{INTRODUCTION}

Today, with the advances in aerospace industry, more advanced materials such as superalloys and composite materials are widely used in aviation engine [1]. Titaniumbased alloys are a group of high-performance materials which have superior properties to fulfill special requirements [2] such as light weight with very high strength-to-weight ratios, reliability in hot environments [3-4].

As the high quality of components surface is the main objective in aerospace industry, surface integrity is an important factor to study for high reliability levels [5-6]. Surface roughness is an important parameter for measuring surface integrity as it has a direct relationship with the service life of parts [7-8]. Therefore, many studies have been conducted on investigating surface roughness and its correlation with machining conditions when turning Ti6Al4V [9-10].

\footnotetext{
${ }^{1}$ Lecturer assistant in Production Engg. Dept., Faculty of Engg., Port Said University, corresponding author, email: Alshymaa.gamal@eng.psu.edu.eg

${ }^{2}$ Professor of production engineering, Helwan University. email: barakatazza5@hotmail.com

${ }^{3}$ Lecturer, Production Engg. Dept., Faculty of Engg., Port Said University. Email:samar.abaas@eng.psu.edu.eg

${ }^{4}$ Professor of Production Engg., Faculty of Engg., Port Said University. email: nassef12@eng.psu.edu.eg

DOI: $10.21608 /$ pserj.2020.32857.1045
}

Many researchers studied the effect of machining conditions entailing direct influences such as process parameters and tool properties $[6,11]$ and indirect conditions affected surface roughness during machining such as cutting force, generated temperature and tool wear by machining $[12,13]$. Nithyanandam et al. [14], studied the effect of process parameters on generated surface roughness by turning tests of Ti6Al4V alloys. The results showed that smoother surface was obtained by low feed rate and high cutting speed with a slight impact of depth of cut on surface roughness. Other researchers used modeling and optimization techniques to optimize surface roughness when turning titanium-based alloys. VenkataRamana et al. [15], followed Taguchi design of experiment and analysis of variance (ANOVA) to optimize machining parameters influencing surface roughness. It was found that feed rate was the most significant parameter that affected surface roughness and the interactions between process parameters had also a high effect. Rajaparthiban et al. [16], used artificial neural network (ANN) to surface roughness modelling by varying process parameters the results showed a higher relationship between measured surface roughness and predicted metal removal rate (MRR) using different process parameters. Regards to the effect of tool geometries on measured surface roughness Kumar et al. [7] reported that nose radius has a significant effect on surface roughness. Jagadesh et al. [17] stated that the surface roughness 
increases at values of feed rates and depths of cut lower than cutting edge radius of tool. Khan et al. [18] investigated turning of titanium-based alloys with a novel chamfered insert, the results showed that chamfered insert recorded good results on measured surface roughness.

Cutting tool materials have an important impact on cutting performance especially when machining difficult-to-cut materials [19]. Selecting a tool of target material with varying cutting conditions can influence tool life, surface finishing of parts and power consumption during machining [20]. Some studies compared the effect of cutting inserts on machining performance as well as obtained surface roughness when turning titanium-based alloys. Ren et al. [21], conducted experimental work on turning of titanium alloy using two different materials of cutting insert namely; PCD and PCBN. It was found that PCD tools showed better performance on tool wear and tool life more than PCBN tool. Niknam et al. [22], studied the performance of two different insert types namely; carbide and CBN insert. The results showed that at high cutting speed, better performance was found by CBN insert in term of surface roughness. Qin et al. [23] studied the coating conditions of insert by using three different insert types; uncoated, PVD and CVD coated carbide insert. It was found that CVD coated insert showed a better surface roughness.

Other studies used different techniques to improve surface roughness such as using ultrasonic assisted turning [24] and cooling system [25]. Liu et al. [26], studied turning of Ti6Al4V alloys using cool air gun cooling system which showed improvement on surface roughness. Ali et al. [27], studied turning of Ti6Al4V using minimal nano-lubrication. The results showed that minimum values of surface roughness were obtained by more sustainable use of nanolubricants in turning Ti6Al4V. Ramana et al. [28] reported that minimum quantity lubrication (MQL) showed better results of surface roughness more than dry and flood machining. The same results were found by Rahman et al. [29]. Revuru et al. [30] used MQL with different cutting fluid conditions on turning of Ti6Al4V. The results showed a slight influence on surface roughness by MQL technique. While different results were found in other studies of the effect of cooling system on obtained surface roughness, Rubio et al. [31], studied turning of Ti6Al4V alloys with three different cooling conditions namely; dry, cold air and MQL cooling systems and reported that no noticeable effect was found by cooling conditions on surface roughness. Also, An et al. [32] stated that a slight lower effect on surface roughness was found by turning with flood cooling. Besides, using cooling systems in machining is not preferred by researchers and became turning to dry machining for serving the environment and saving power and costs.

From literature review, tool wear, generated temperature and cutting force when turning $\mathrm{Ti} 6 \mathrm{Al} 4 \mathrm{~V}$ using various tool materials were studied and a few researches aimed to study obtained surface roughness by different cutting tool materials. Therefore, this paper aimed to optimize the surface roughness of machining titanium based alloy using $\mathrm{CBN}$ and coated ceramic inserts. Surface roughness was measured in two cases with different cutting parameters on dry condition.

The present of the paper is organized as follows; section 2 shows experimental set up and procedure. Section 3 presents the experimental results and analysis to optimize surface roughness by both inserts. in Section 4 , The specific conclusions are drowned.

\section{EXPERIMENTAL WORK}

Ti6Al4V alloy was used as a target material for turning tests. Solid rods of material with $25 \mathrm{~mm}$ outer diameter are used and the cutting length for each trail was $30 \mathrm{~mm}$. Vickers test was carried out to measure hardness; the average hardness value was $\left(367 \mathrm{~V}_{30}\right)$. Chemical composition of material was examined, see Table 1 . The physical properties of Ti6Al4V are given in Table 2.

Table 1. Chemical composition of Ti6Al4V material

\begin{tabular}{|c|cccc|}
\hline Element & $\mathbf{T i}$ & $\mathbf{A l}$ & $\mathbf{V}$ & $\mathbf{C u}$ \\
\hline $\boldsymbol{\%}$ & 89.4 & 5.74 & 4.4 & 0.0685 \\
\hline Element & $\mathbf{F e}$ & $\mathbf{S n}$ & $\mathbf{S i}$ & $\mathbf{W}$ \\
\hline $\boldsymbol{\%}$ & 0.162 & 0.014 & 0.0119 & 0.165 \\
\hline
\end{tabular}

Table 2. The physical properties of Ti6Al4V [33]

\begin{tabular}{|l|c|}
\hline \multicolumn{2}{|c|}{ Ti6AL4V } \\
\hline Density (g/cm3) & 4.43 \\
\hline Tensile elastic modulus (GPa) & 110 \\
\hline Tensile strength (MPa) & 931 \\
\hline Yield strength (MPa) & 862 \\
\hline Elongation (\%) & 14 \\
\hline Thermal conductivity at $20{ }^{\circ} \mathrm{C}(\mathrm{W} / \mathrm{m} \mathrm{K})$ & 7.3 \\
\hline Specific heat $20-100{ }^{\circ} \mathrm{C}(\mathrm{J} / \mathrm{Kg} \mathrm{K})$ & 709 \\
\hline
\end{tabular}

Two types of inserts by Taegu Tec were used for experiments with different materials and same geometry, see Fig. 1. The first insert was ceramic insert is ceramic insert with $\mathrm{AL}_{2} \mathrm{O}_{3}+\mathrm{TiCN}$ coated layer. The second insert was $\mathrm{CBN}$ (KB90) insert. Both inserts have $55^{\circ}$ cutting edge angle, $0^{\circ}$ rake angle and $0.8 \mathrm{~mm}$ nose radius. Tool holder (PDJNR 2020 K15) by Taegu Tec was used.

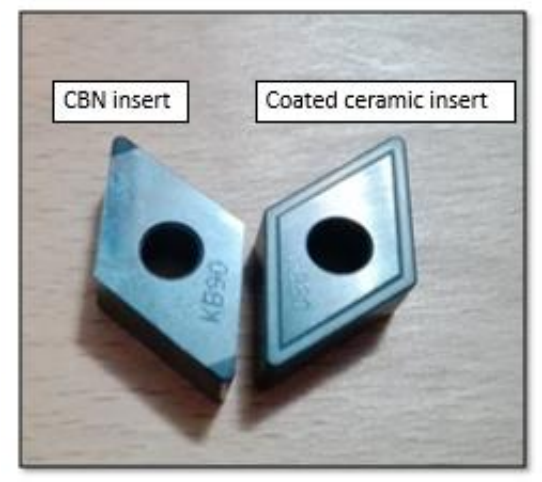

Figure 1: The two different inserts used in experiments 
Turning operations were conducted on a CNC lathe with 6000 maximum rotational speed of spindle and $5.5 \mathrm{KW}$ spindle motor. Figure 2 shows $\mathrm{CNC}$ lathe used for experiments.

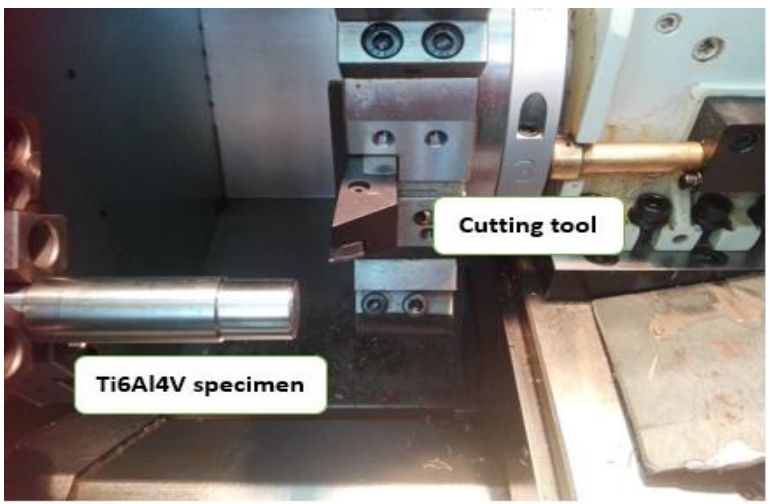

Figure 2: Experimental test rig

Design of experiments based on Taguchi method design $\left(\mathrm{L}_{9}\right)$ on measuring surface roughness. The process parameters were feed rate, cutting speed and depth of cut. Table 3 present Taguchi method design $\left(\mathrm{L}_{9}\right)$ for the three factors and with three levels. All experiments were carried out under dry conditions.

Table 3. Taguchi method design (Lg) for variable process parameters

\begin{tabular}{|c|c|c|c|}
\hline Run & $\begin{array}{c}\mathrm{F} \\
(\mathrm{mm} / \mathrm{rev})\end{array}$ & $\begin{array}{c}\mathrm{V} \\
(\mathrm{m} / \mathrm{min})\end{array}$ & $\begin{array}{c}\mathrm{d} \\
(\mathrm{mm})\end{array}$ \\
\hline 1 & 0.1 & 50 & 0.15 \\
\hline 2 & 0.1 & 75 & 0.2 \\
\hline 3 & 0.1 & 100 & 0.25 \\
\hline 4 & 0.15 & 50 & 0.2 \\
\hline 5 & 0.15 & 75 & 0.25 \\
\hline 6 & 0.15 & 100 & 0.15 \\
\hline 7 & 0.2 & 50 & 0.25 \\
\hline 8 & 0.2 & 75 & 0.15 \\
\hline 9 & 0.2 & 100 & 0.2 \\
\hline
\end{tabular}

The results of surface roughness $(\mathrm{Ra})$ were measured by Surtronic (3 stylus) profilometer as shown in Fig. 3 with cut length of $0.8 \mathrm{~mm}$. The measured roughness is an average of ten readings taken over the machined length.

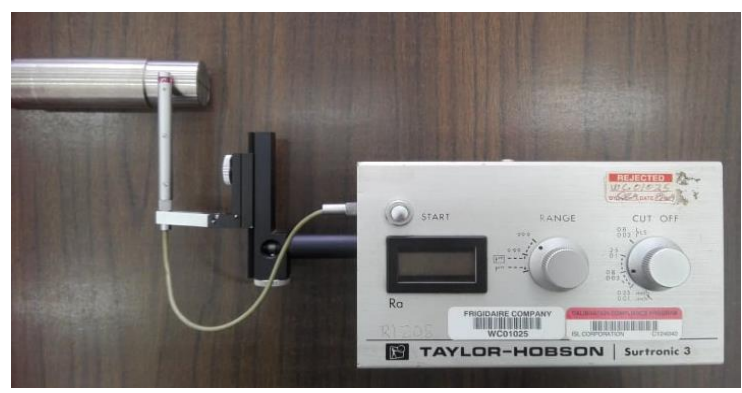

Figure 3: Surtronic (3 stylus) profilometer

\section{RESULTS AND DISCUSSION}

All results of measured surface roughness were collected and analyzed by MINITAB software to calculate results of Taguchi analysis, analysis of variance (ANOVA) and graphical analysis. From Taguchi analysis. Figure 4 shows all results of measured surface roughness for all trails using CBN and coated ceramic inserts in addition to calculated metal removal rate (MRR). Comparison between two inserts with respect MRR is important for measuring surface roughness corresponding productivity. The graph indicates that coated ceramic insert gave better results of surface roughness more than the results obtained by $\mathrm{CBN}$ one for all trails. Also, the results showed improvement in surface roughness by $34 \%$ when using coated ceramic insert than using CBN insert at the same cutting conditions.

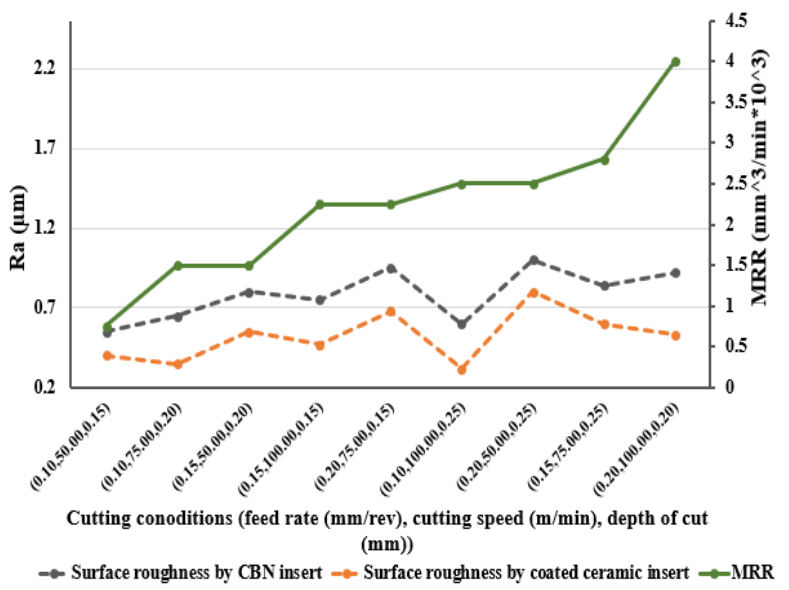

Figure 4: Material removal rate (MRR) and measured surface roughness of Ti6Al4V specimens machined by coated ceramic and $\mathrm{CBN}$ inserts

It was observed that the minimum surface roughness $(\mathrm{Ra}=$ $0.315 \mu \mathrm{m}$ ) was obtained by coated ceramic tool at feed rate of $0.1 \mathrm{~mm} / \mathrm{rev}$, cutting speed of $100 \mathrm{~m} / \mathrm{min}$ and depth of cut of $0.25 \mathrm{~mm})$ with high MRR $\left(2.5 * 10^{\wedge} 3 \mathrm{~mm}^{\wedge} 3 / \mathrm{min}\right)$. While minimum obtainable surface roughness by $\mathrm{CBN}$ insert $(\mathrm{Ra}=$ $0.55 \mu \mathrm{m})$ at $0.1 \mathrm{~m} / \mathrm{rev}$ feed rate, $50 \mathrm{~m} / \mathrm{min}$ cutting speed and $0.15 \mathrm{~mm}$ depth of cut led to low MRR of $0.75 * 10^{\wedge} 3$ $\mathrm{mm}^{\wedge} 3 / \mathrm{min}$. Besides, maximum MRR $\left(0.4 * 10^{\wedge} 3\right.$ $\mathrm{mm}^{\wedge} 3 / \mathrm{min}$ ) was obtained with an acceptable measured surface roughness $\mathrm{Ra}$ of $0.6 \mu \mathrm{m}$ and $0.84 \mu \mathrm{m}$ by coated ceramic and $\mathrm{CBN}$ inserts, respectively.

\subsection{Main Effects of Process Parameters}

Fig. 5. presents the main effect of individual process parameter namely; feed rate, cutting speed and depth of cut on measured surface roughness when using coated ceramic insert. It was obviously found that surface roughness increased with increasing feed rate that agrees with previous studies [14-15] which reported that feed rate has the most significant effect on surface roughness, as the larger feed rate leads to rougher surface. Cutting speed and depth of cut 
showed a lower impact on surface roughness compared with feed rate. It was found that surface roughness improved with increasing cutting speed. Some studies explained this improvement by the softening of target material which occurred due to the increase of the cutting temperature with higher cutting speed. This can reduce cutting force and fluctuant by force result in smoother surface [34-35]. Owing to the effect of depth of cut on measured surface roughness, a slight decrease of it was found by increasing cut depth from 0.15 to $0.2 \mathrm{~mm}$, Then the surface roughness increases with increasing cut depth from 0.2 to $0.25 \mathrm{~mm}$. the increase in surface roughness at lowest value of depth of cut is due to the ploughing and rubbing actions which occurs at low depth of cut and large nose radius. Although a large nose radius has effective impact on improving surface roughness, it has a negative effect on machining performance when machining at lower depth of cut. Also, a higher cut depth led to a rougher surface. That is may due to higher chatter and vibration produced during process by higher depth of cut which lead to higher surface roughness [36].

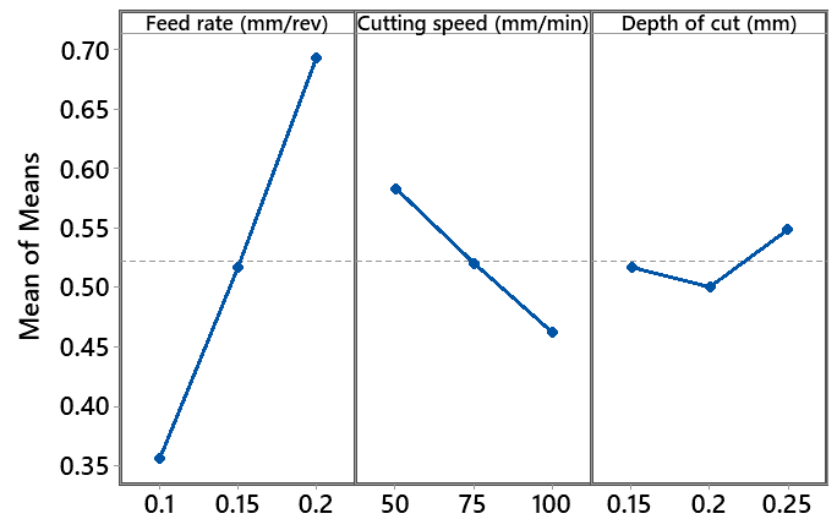

Figure 5: Effect of process parameters on surface Roughness using coated ceramic insert

Similarly, Fig. 6. presents the effect of individual parameters on Ra using CBN insert. It was found the same trend of the effect of feed rate on surface roughness that found by coated ceramic insert in the case of CBN insert. The feed rate has a linear relationship with surface roughness. Regarding the effect of cutting speed on surface roughness (shown in Fig.5), a different trend was observed in Fig.6. It was found that the surface roughness increased with increasing cutting speed from 50 to $75 \mathrm{~mm} / \mathrm{min}$. Then it decreased at higher cutting speeds. At low cutting speed the surface roughness increased with increasing cutting speed. This is due to high chatter and vibrations at higher cutting speed [36]. However, at higher cutting speeds the surface roughness decreased, due to thermal softening [34]. Owing to the effect of depth of cut, the surface roughness is higher using CBN insert than in using coated ceramic one. It was observed that $\mathrm{Ra}$ increased when the depth of cut changed from 0.15 to $0.2 \mathrm{~mm}$ followed by a higher increase to reach the highest depth of cut.

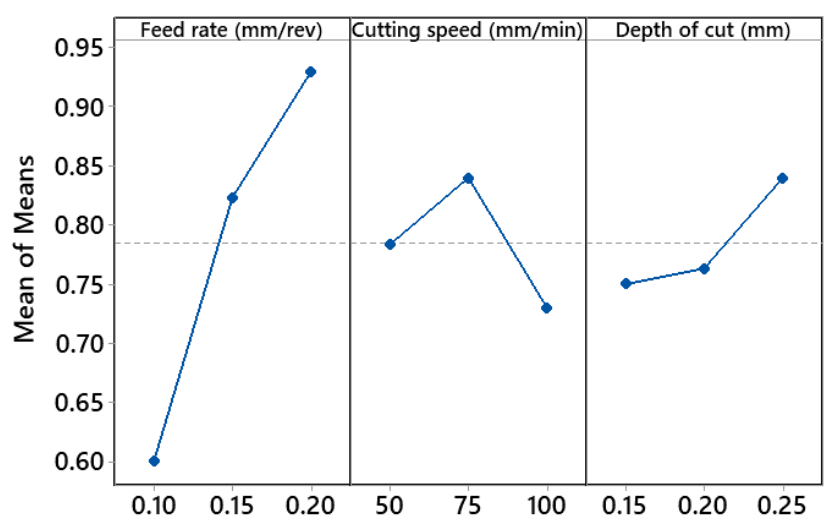

Figure 6: Effect of process parameters on surface Roughness using CBN insert

From the results of surface roughness which found by two cutting inserts, in case of coated ceramic insert, minimum surface roughness was found at highest cutting speed 100 $\mathrm{mm} / \mathrm{min}$, low feed rate $0.1 \mathrm{~mm} / \mathrm{rev}$ and moderate value of depth of cut $0.2 \mathrm{~mm}$. On the other hand, minimum surface roughness was achieved in case of CBN insert, at highest cutting speed $100 \mathrm{~m} / \mathrm{min}$ and low feed rate $0.1 \mathrm{~mm} / \mathrm{rev}$ and depth of cut $0.15 \mathrm{~mm}$. Regarding ANOVA analysis, Table 4 and Table 5 show the most significant parameters affecting surface roughness for two types of inserts. The feed rate has the highest impact on surface roughness with p-value of 0.009 using coated ceramic insert, and $\mathrm{p}$-value of 0.008 using CBN insert. The cutting speed is the second significant parameter affecting surface roughness with p-value of 0.065 and 0.069 using ceramic and CBN inserts, respectively. The depth of cut has the lowest effect with p-value of 0.087 for $\mathrm{CBN}$ insert, and an insignificant effect in the case of coated ceramic insert with p-value 0.3

Table 6: Analysis of variance results by coated ceramic insert

\begin{tabular}{|cccccc|}
\hline Parameter & DF & Adj SS & Adj MS & $\begin{array}{c}\text { F- } \\
\text { Value }\end{array}$ & $\begin{array}{c}\text { P- } \\
\text { Value }\end{array}$ \\
\hline $\begin{array}{c}\text { Feed rate } \\
(\mathrm{mm} / \mathrm{rev})\end{array}$ & 2 & 0.171817 & 0.085908 & 110.85 & 0.009 \\
\hline $\begin{array}{c}\text { Cutting speed } \\
\text { (mm/min) }\end{array}$ & 2 & 0.022217 & 0.011108 & 14.33 & 0.065 \\
\hline $\begin{array}{c}\text { Depth of cut } \\
\text { (mm) }\end{array}$ & 2 & 0.003617 & 0.001808 & 2.33 & 0.300 \\
\hline Error & 2 & 0.001550 & 0.000775 & & \\
\hline Total & 8 & 0.199200 & & \\
\hline
\end{tabular}

Table 6: Analysis of variance results by CBN insert

\begin{tabular}{|cccccc|}
\hline Parameter & DF & Adj SS & Adj MS & $\begin{array}{c}\text { F- } \\
\text { Value }\end{array}$ & $\begin{array}{c}\text { P- } \\
\text { Value }\end{array}$ \\
\hline $\begin{array}{c}\text { Feed rate } \\
\text { (mm/rev) }\end{array}$ & 2 & 0.170156 & 0.085078 & 125.52 & 0.008 \\
\hline $\begin{array}{c}\text { Cutting speed } \\
\text { (mm/min) }\end{array}$ & 2 & 0.018156 & 0.009078 & 13.39 & 0.069 \\
\hline
\end{tabular}




\begin{tabular}{|c|c|c|c|}
\hline $\begin{array}{l}\text { Depth of cut } \\
(\mathrm{mm})\end{array}$ & $\begin{array}{lll}2 & 0.014156 & 0.007078\end{array}$ & 10.44 & 0.087 \\
\hline Error & $\begin{array}{ll}2 & 0.0013560 .000678 \\
\end{array}$ & & \\
\hline Total & $\begin{array}{ll}8 & 0.203822 \\
\end{array}$ & & \\
\hline
\end{tabular}

\subsection{Interactions of Process Parameters}

In this section, the effect of interactions of process parameters is discuss. The main effect of individual process parameter can give different trends by changing the other parameters.

Fig.7 presents the effect of interaction of feed rate and depth of cut on surface roughness using ceramic insert. Higher variation of surface roughness with feed rate occurred at $0.25 \mathrm{~mm}$ depth of cut. Maximum surface roughness was observed at highest values of feed rate $(0.2$ $\mathrm{mm} / \mathrm{rev})$ and depth of cut $(0.25 \mathrm{~mm})$. Minimum value was at a high depth of cut $(0.25 \mathrm{~mm})$ and low feed rate $(0.1$ $\mathrm{mm} / \mathrm{rev}$ ). At low feed rate, smallest depth of cut resulted in rougher surface than that obtained by other cut depths.

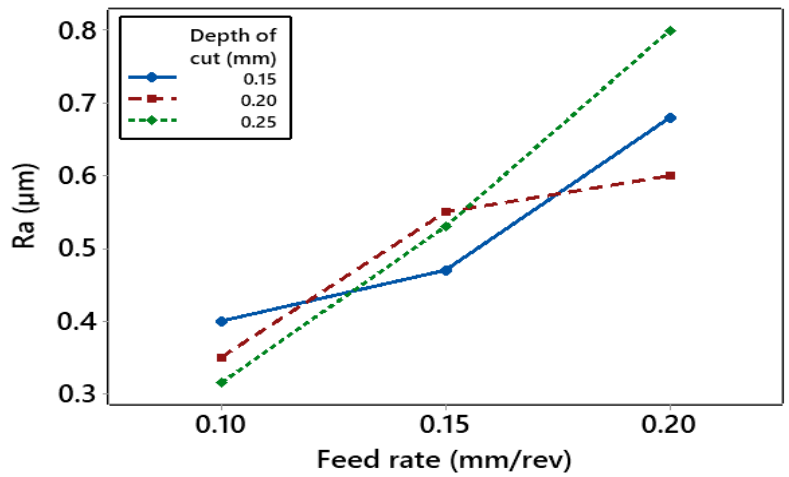

Figure 7: Effect of interaction of feed rate and depth of cut on surface roughness when using coated ceramic insert

Regards to the case of CBN insert, Fig. 8 shows the effect of interaction of feed rate and depth of cut on measured surface roughness. smoother surface was found by lowest depth of cut $(0.15 \mathrm{~mm})$ than other cut depths at feed rates; 0.1 and $0.15 \mathrm{~mm} / \mathrm{rev}$ while maximum surface roughness at highest feed rate $(0.2 \mathrm{~mm} / \mathrm{rev})$ was achieved by depth of cut of $0.25 \mathrm{~mm}$.

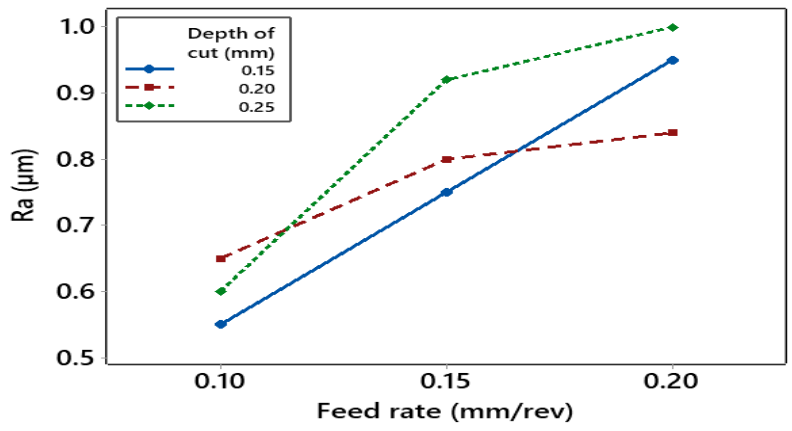

Figure 8: Effect of interaction of feed rate and depth of cut on surface roughness when using $\mathrm{CBN}$ insert
Fig. 9 illustrates the effect of interaction of depth of cut and cutting speed on surface roughness, when using coated ceramic. Different trends of the effect of depth of cut on surface roughness with different cutting speeds was observed. At lower cutting speed, a proportional relationship between depth of cut and surface roughness was noticed. This may be due to a higher force and vibration at higher depth of cut [37]. On the other hand, at higher cutting speed this may not take place due to material softening because of high heat generation $[34,38]$. Highest surface roughness was found at $0.25 \mathrm{~mm}$ depth of cut and $50 \mathrm{~mm} / \mathrm{min}$ cutting speed. Combination of higher values of cutting speed and depth of cut resulted in rougher surface. Better results were found at high cutting speed and depth of cut. Minimum surface roughness results using higher cutting speed and $0.25 \mathrm{~mm}$ depth of cut.

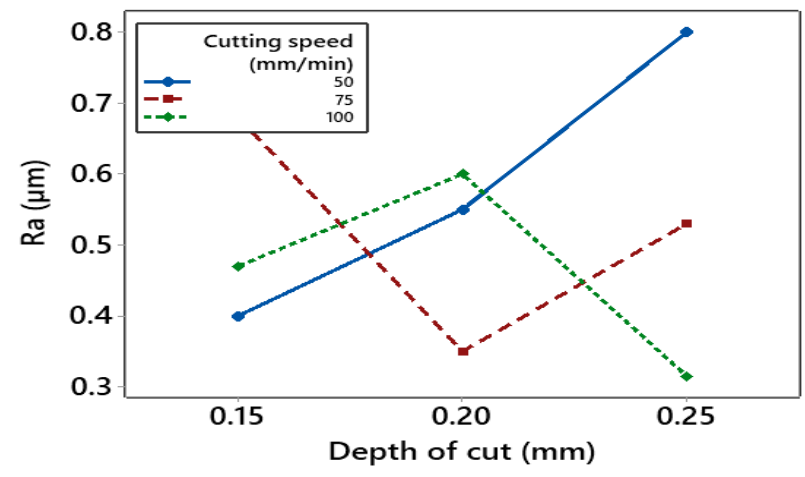

Figure 9: Effect of interaction of cutting speed and depth of cut on surface roughness when using coated ceramic insert

At the case of using CBN insert, Fig. 10 shows the effect of interaction of cutting speed and depth of cut on measured surface roughness. Same trends of interaction between these two process parameters that obtained by coated ceramic insert was found when using CBN insert. The minimum surface roughness that found in this case was occurred by combination of low cutting speed $(50 \mathrm{~m} / \mathrm{min})$ and low depth of cut $(0.15 \mathrm{~mm})$. Otherwise the maximum surface roughness occurred at low cutting speed $(50 \mathrm{~m} / \mathrm{min})$ and high depth of cut $(0.25 \mathrm{~mm})$.

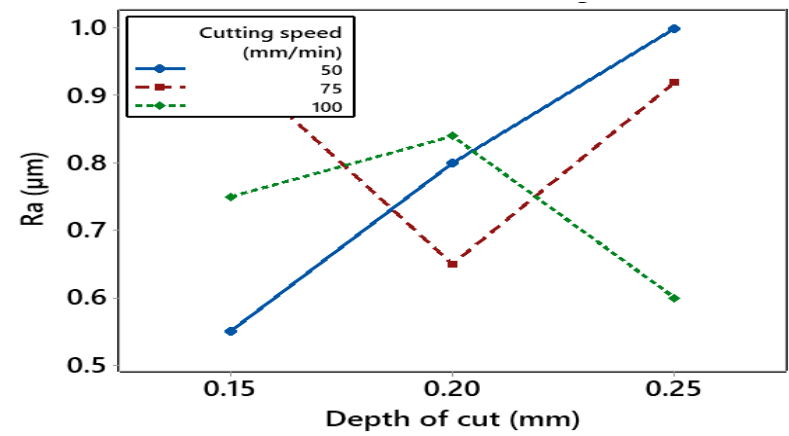

Figure 10: Effect of interaction of cutting speed and depth of cut on surface roughness when using CBN insert 
Fig. 11 shows the effect of interaction of cutting speed and feed rate on surface roughness by using coated ceramic. It was found that surface roughness decreased by increasing cutting speed for all values of feed rates. A noticeable variation in surface roughness at different cutting speed was found at depth of cut $(0.25 \mathrm{~mm})$, while a fewer varying values of surface roughness was found when depth of cut of $0.15 \mathrm{~mm}$ was applied.

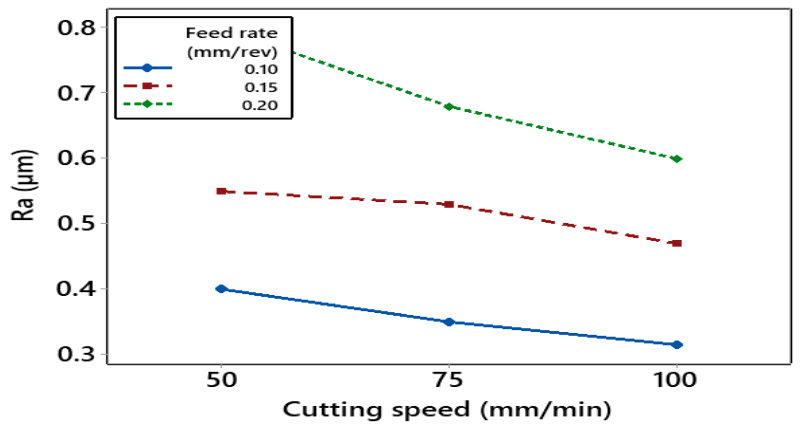

Figure 11: Effect of interaction of feed rate and cutting speed cut on surface roughness when using coated ceramic insert

At the case of coated ceramic insert, Fig. 12 shows the effect of interaction of feed rate and cutting speed on measured surface roughness. Same trend of relationship between cutting speed and surface roughness that found by coated ceramic insert was observed in the case of CBN insert at higher feed rate while different trends were observed at lower feed rates. Obvious decrease in surface roughness was found by low cutting speed $(50 \mathrm{~m} / \mathrm{min})$ at lower values of feed rates $(0.1$ and $0.15 \mathrm{~mm} / \mathrm{rev})$. minimum surface roughness in this case was found by combination between low feed rate $(0.1 \mathrm{~mm} / \mathrm{rev})$ and low cutting speed $(50 \mathrm{~m} / \mathrm{min})$ and the maximum value was found at low cutting speed (50 $\mathrm{m} / \mathrm{min})$ and high feed rate $(0.2 \mathrm{~mm} / \mathrm{rev})$.

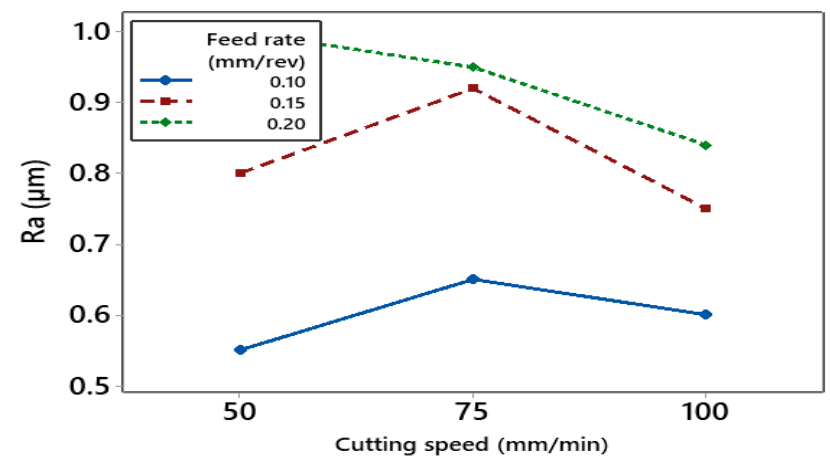

Figure 12: Effect of interaction of feed rate and cutting speed cut on surface roughness when using CBN insert

\section{CONCLUSION}

This paper has presented a comparison between coated ceramic and $\mathrm{CBN}$ inserts on surface roughness obtained by turning tests. The machining operations were carried out with varying process parameters, entailing feed rate, cutting speed and depth of cut under dry conditions. The main conclusions are as follows.

1. Improvement in surface roughness by $34 \%$ when using coated ceramic insert than those achieved by CBN inserts.

2. CBN insert gave a better result at smallest depth of cut $(0.15 \mathrm{~mm})$ while coated ceramic tool gave a minimum surface roughness at depth of cut $0.2 \mathrm{~mm}$.

3. For both cutting inserts, combination between low cutting speed $(50 \mathrm{~m} / \mathrm{min})$ and low depth of cut $(0.15 \mathrm{~mm})$ gave a smoother surface while low cutting speed $(50$ $\mathrm{m} / \mathrm{min})$ with combination with high depth of cut $(0.25$ $\mathrm{mm}$ ) gave a rougher surface.

\section{CREDIT AUTHORSHIP CONTRIBUTION STATEMENT}

Al Shimaa Abdelnasser: Methodology, Investigation, Formal analysis, Writing - Original Draft Azza Barakat: Conceptualization, Methodology, Writing - review editing, Supervision Samar Elsanabary: Methodology, Writing review \& editing, Supervision, Ahmed Nassef : Writing review \& editing, Supervision

\section{DECLARATION OF COMPETING INTEREST}

The authors declare that there is no conflict of interest regarding the publication of this paper.

\section{ACKNOWLEDGMENTS}

The authors would like to thank Prof. Assistant Ahmed Elkaseer from the Faculty of Engineering, Port Said University for the scientific support he provided and the knowledge he shares with us to pursue this research.

\section{REFERENCES}

[1] R. N. Patel and A. Ranjan, "Advanced Techniques in Machining of Aerospace Superalloys: A Review", International Journal of Advance Research in Engineering, Science \& Technology 2 (5), 2015, PP. 1-6

[2] M. Goiogana and A. Elkaseer, "Self-Flushing in EDM Drilling of Ti6Al4V Using Rotating Shaped Electrodes". Materials (12) 989. 2019.

[3] E. Tascioglu, A. Gharibi and Y. Kaynak, "High speed machining of near-beta titanium Ti-5553 alloy under various cooling and lubrication conditions", The International Journal of Advanced Manufacturing Technology (102), 2019, pp 4257-4271

[4] J. E. Abu Qudeini, A. I. Mourad, A. Ziout, M. H. Abidi and A. Elkasser, "Electric discharge machining of titanium and its alloys: review", The International Journal of Advanced Manufacturing Technology (96), 2018, pp. 1319:1339

[5] A. T. Abbas, M. M. El Rayes, M. Luqman, N. Naeim, H. Hegab and A. Elkaseer, "On the Assessment of Surface Quality and Productivity Aspects in Precision Hard Turning of AISI 4340 Steel Alloy: Relative Performance of Wiper vs. Conventional Inserts", Materials (13) 2036, 2020.

[6] B. Wang and Z. Liu, "Influences of tool structure, tool material and tool wear on machined surface integrity during turning and milling of titanium and nickel alloys: a review", 
The International Journal of Advanced Manufacturing Technology (98). 2018, pp. 1925-1975

[7] S. M. Ravi Kumar and S. K. Kulkarni, "Analysis of Hard Machining of Titanium Alloy by Taguchi Method", Materials Today: Proceedings (4), 2017, pp. 10729-10738

[8] A. Elkaseer, A. Abdelaziz, M. Saber and A. Nassef, "FEM-Based Study of Precision Hard Turning of Stainless Steel 316L", Materials 2019 (12) 2522, 2019.

[9] S. Elsanabary, A. Elkaseer, S. Abd-Rabbo, M. Abd Elsalam and Sh. Abdou, "Modelling and experimental validation of surface roughness in precision turning of dualphase materials considering process uncertainties", International Journal on Interactive Design and Manufacturing (13), 2018, pp. 59-74

[10] A.M. Elkaseer, K.B. Popov, M. Negm, S.S. Dimov1 and R. Minev, "Material Microstructure Effect-Based Simulation Model for the Surface Generation Process in Micro-milling", Conference: ICOMM/4M 2010

[11] S. H. You, J. H. Lee and S. H. Oh, "A Study on Cutting Characteristics in Turning Operations of Titanium Alloy used in Automobile", International Journal of Precision Engineering and Manufacturing (20), 2019, pp. 209-216

[12] G. D'Mello a, P. Srinivasa Pai b, A. Prashanth, "Surface Roughness Analysis in High Speed Turning of Ti-6Al-4V Using Coated Carbide Inserts: Experimental and Modeling Studies", Tribology in Industry 40 (3), 2018, pp. 457-476

[13] L. N. Devin, N. E. Stakhniv, A. S. Antoniuk, S. V. Rychev and V. N. Nechiporenko, "The Influence of Cutting Speed on Cutting Temperatures and Forces in Fine Turning of VT1_0 Titanium Alloy by a PCD Tool" Journal of Superhard Materials 4 (2), 2019, pp. 119-125.

[14] J. Nithyanandam, S. LaIDas and K.Palanikumar, "Surface roughness analysis in turning of titanium alloy by nanocoated carbide insert", Procedia Materials Science (5), 2014, pp. 2159-2168

[15] M. VenkataRamana and Y. ShanmukaAdity, "Optimization and influence of process parameters on surface roughness in turning of titanium alloy", Materials Today: Proceedings (4), 2017, pp. 1843-1851

[16] J. Rajaparthiban and A. Naveen Sait, 2018, "Experimental Investigation on Machining of Titanium Alloy (Ti 6Al 4V) and Optimization of its Parameters using ANN", Mechanika 24(4), pp. 449-455

[17] T. Jagadesh and G. L. Samuel, "Investigation into cutting forces and surface roughness in micro turning of titanium alloy using carbide tool", Procedia Materials Science (5), 2014, pp. 2450-2457

[18] S. A. Khan, M. Z. Afzal, M. Q. Saleem, K. H. Hashmi and Z. Ghulam, "Performance evaluation of novel chamfered inserts in high-feed turning of Ti-6Al-4V alloy", The International Journal of Advanced Manufacturing Technology (97), 2018, pp. 2319-2329

[19] M.S.I. Chowdhury, B. Bose, K. Yamamoto, L.S. Shuster, J. Paiva, G.S. Fox-Rabinovich, S.C. Veldhuis, "Wear performance investigation of PVD coated and uncoated carbide tools during high-speed machining of TiAl6V4 aerospace alloy”, wear (446-447) 203168, 2020.
[20] E. Kaya and İ. Kaya, "Tool wear progression of PCD and PCBN cutting tools in high speed machining of NiTi shape memory alloy under various cutting speeds", Diamond and Related Materials (105) 107810, 2020.

[21] Z. Ren, Shengguan, Y. Zhang, F. Sun, X. Li and C. Yang, "Machining performance of PCD and PCBN tools in dry turning titanium alloy Ti-6Al-0.6Cr-0.4Fe-0.4Si-0.01B", The International Journal of Advanced Manufacturing Technology (102) 2019, pp. 2649-2661

[22] S. A. Niknam, S. Kamalizadeh, A. Asgari and M. Balazinski, "Turning titanium metal matrix composites (TiMMCs) with carbide and CBN inserts", The International Journal of Advanced Manufacturing Technology (97), 2018, pp. 253-265

[23] S. Qin, Z. Li, G. Guo, Q. An, M. Chen and W. Ming, "Analysis of Minimum Quantity Lubrication (MQL) for Different Coating Tools during Turning of TC11 Titanium Alloy", Materials (9) 804, 2016, pp. 1-13

[24] R. Muhammad, M. S. Hussain, A. Maurotto, C. Siemers, A. Roy and V. V. Silberschmidt, "Analysis of a free machining $\alpha+\beta$ titanium alloy using conventional and ultrasonically assisted turning", Journal of Materials Processing Technology (214), 2014, pp. 906-915

[25] Z. Lu, D. Zhang, X. Zhang and Z. Peng, "Effects of high-pressure coolant on cutting performance of high-speed ultrasonic vibration cutting titanium alloy", Journal of Materials Processing Tech (279) 116584, 2020.

[26] N. Liu, K. Chiang and C. Hung, "Modeling and analyzing the effects of air-cooled turning on the machinability of Ti-6Al-4V titanium alloy using the cold air gun coolant system", International Journal of Advanced Manufacturing Technology (67) 2013, pp. 1053-1066

[27] M. A. M. Ali, A. I. Azmi, A. N. M. Khalil and K. W. Leong, "Experimental study on minimal nanolubrication with surfactant in the turning of titanium alloys", International Journal of Advanced Manufacturing Technology (92), 2017, pp. 117-127

[28] M. V. Ramana, "Optimization and Influence of Process Parameters on Surface Roughness in Turning of Titanium Alloy under Different Lubricant Conditions", Materials Today: Proceedings (4), 2017, pp. 8328-8335

[29] S. S. Rahman, M. Z. Ibne Ashraf, A. N. Amin, M.S. Bashar, M. F. K. Ashik and M. Kamruzzaman, "Tuning nanofluids for improved lubrication performance in turning biomedical grade titanium alloy", Journal of Cleaner Production (206), 2019, pp. 180-196

[30] R. S. Revuru, J. Z. Zhang, N. R. Posinasetti and T. Kidd, "Optimization of titanium alloys turning operation in varied cutting fluid conditions with multiple machining performance characteristics", International Journal of Advanced Manufacturing Technology (95), 2018, pp. 14511463

[31] E. M. Rubio, A. Bericua, B. de Agustina and M. M. Marina, "Analysis of surface roughness of titanium pieces obtained by turning using cooling systems", Procedia CIRP (79), 2019, pp. 76-84

[32] Q.L. An, Y. C. Fu and J. H. Xu, "Experimental study on turning of TC9 titanium alloy with cold water mist jet 
cooling", International Journal of Machine Tools and Manufacture (51), 2011, pp. 549-555

[33] J. P. Davim, "Machining of Titanium Alloys", Springer, 2014.

[34] S. Sun, M. Brandt and M. S. Dargusch, "Characteristics of cutting forces and chip formation in machining of titanium alloys", International Journal of Machine Tools and Manufacture (49), 2009, pp 561-568

[34] F. Xiuli, L. Wenxing, P. Yongzhi and L. Wentao, "Morphology evolution and micro-mechanism of chip formation during high-speed machining", The International Journal of Advanced Manufacturing Technology (98), 2018, pp 165-175

[35] J.H. Lange and N.H. Abu-Zahra, "Tool Chatter Monitoring in Turning Operations Using Wavelet Analysis of Ultrasound Waves", The International Journal of Advanced Manufacturing Technology (20), 2002, pp. 248254

[36] J.H. Lange and N.H. Abu-Zahra, "Tool Chatter Monitoring in Turning Operations Using Wavelet Analysis of Ultrasound Waves", The International Journal of Advanced Manufacturing Technology (20), 2002, pp. 248254

[37] S. L. M. R. Filho, R. B. D. Pereira, C. H. L. and L. C. Brandão, "Investigation and modelling of the cutting forces in turning process of the Ti-6Al-4V and Ti-6Al-7Nb titanium alloys", The International Journal of Advanced Manufacturing Technology (101), 2019, pp. 2191-2203

[38] A. Elkaseer, S. S., Dimov, K. B., Popov, and R. M. Minev, "Tool Wear in Micro-Endmilling: Material Microstructure Effects, Modeling, and Experimental Validation." ASME. J. Micro Nano-Manuf. December 2014; 2(4): 044502. https://doi.org/10.1115/1.4028077 